\title{
Formation and Investigation of Electrospun PLA Materials with Propolis Extracts and Silver Nanoparticles for Biomedical Applications
}

\author{
Erika Adomavičiūtè, ${ }^{1}$ Solveiga Pupkevičiūtè, ${ }^{1}$ Vaida Juškaitė, ${ }^{2}$ Modestas Žilius, ${ }^{2}$ \\ Sigitas Stanys, ${ }^{1}$ Alvydas Pavilonis, ${ }^{3}$ and Vitalis Briedis ${ }^{2}$ \\ ${ }^{1}$ Faculty of Mechanical Engineering and Design, Kaunas University of Technology, Studentu Street 56, LT-51424 Kaunas, Lithuania \\ ${ }^{2}$ Department of Clinical Pharmacy, Faculty of Pharmacy, Lithuanian University of Health Sciences, Sukilèliu Pr. 13, \\ LT-50161 Kaunas, Lithuania \\ ${ }^{3}$ Institute of Microbiology and Virology, Lithuanian University of Health Sciences, Eiveniu Street 4, LT-50161 Kaunas, Lithuania
}

Correspondence should be addressed to Vitalis Briedis; vitalis.briedis@lsmuni.lt

Received 19 December 2016; Revised 27 February 2017; Accepted 21 March 2017; Published 2 April 2017

Academic Editor: Tamer Uyar

Copyright @ 2017 Erika Adomavičiūte et al. This is an open access article distributed under the Creative Commons Attribution License, which permits unrestricted use, distribution, and reproduction in any medium, provided the original work is properly cited.

An electrospun hydrophilic non-water-soluble biocompatible polylactic acid (PLA) nonwoven material was used as a delivery system for propolis ethanolic extract (PEE) and silver nanoparticles (AgNPs) that are known for their established antiseptic and antimicrobial activity. Combination of PEE and AgNPs in a single product should provide efficient antimicrobial protection and improved wound healing. Evaluations of PEE and AgNPs on morphology of electrospun materials, release kinetics of AgNPs and phenolic compounds, antibacterial properties, and cytotoxicity of electrospun PLA materials were performed. The presence of PEE or/and AgNPs resulted in denser mats formed by thicker PLA fibers. The average diameter of PLA microfibers was $168 \pm 29 \mathrm{~nm}$. The average diameter of microfibers increased to $318 \pm 40$ and $370 \pm 30 \mathrm{~nm}$ when $10 \mathrm{wt} \%$ and $20 \mathrm{wt} \%$ ethanol were added, respectively. Addition of $10 \mathrm{wt} \%$ or $20 \mathrm{wt} \%$ PEE increased the diameter to $282 \pm 25$ and $371 \pm 25 \mathrm{~nm}$, respectively. Suspension of AgNPs also caused the formation of thicker microfibers with $254 \pm 25 \mathrm{~nm}$ diameter. Electrospun PLA microfibers with PEE maintained viability of $\mathrm{HaCaT}$ cells. Testing of antimicrobial activity confirmed the ability of AgNPs containing PLA electrospun materials to inhibit the growth of microorganisms.

\section{Introduction}

Effective wound healing can be improved by topical application of wound covering material for prevention of infection. Appropriate wound dressing is considered as a protective barrier to assist the wound healing process. Electrospun nonwoven materials from nano/microfibers can provide an excellent microenvironment for wound healing. Introduction of new biopolymers and fabrication techniques offers advantageous characteristics of wound dressing materials. Peculiarities of wound type, wound healing time, and physical, mechanical, and chemical properties of the dressing have to be considered in designing a functional wound dressing. The application of such functional wound dressing should result in achieving an increased rate of wound healing and aesthetic repair of the wound $[1,2]$.

Recently, much attention has been focused on polymeric nonwoven wound dressings produced by electrospinning due to their high aspect ratio and porosity [3]. Electrospinning technology is the most commonly used to produce polymer nano/microfiber materials $[2,4,5]$. Electrospinning offers the possibility of fabricating highly interconnected, nonwoven materials from nano/microfibers with diameters in the nanoscale ranges, which are structurally similar to nanofibrillar extracellular matrix proteins [5]. The structure of nano/microfibers and their large surface area, high porosity, nanoscale diameters, and small pore size make them highly attractive for application in biomedicine for tissue 
engineering scaffolds, drug delivery systems, and wound dressings. The abovementioned properties promote cell respiration, skin regeneration, moisture retention, removal of exudates, and homeostasis. Moreover, increased patient compliance and comfort are provided by reduced need to change the dressing which is produced by electrospinning of biodegradable polymers. Incorporation of therapeutic and/or antimicrobial agents in nano/microfibers can functionalize electrospun nonwoven materials offering personalized dressings for any wound surface $[2,4]$.

Natural polymers are derived from renewable sources and are intrinsically biocompatible and biodegradable. Gelatin, collagen, chitosan, hyaluronic acid, and silk fibroin have been used for electrospinning of nonwoven materials for localized drug delivery systems [1, 2, 6-10]. Many of these polymers demonstrate specific properties that promote wound healing. Synthetic polymers commonly used for wound healing applications include polyethylene oxide (PEO) [6], polylactide (PLA) $[1,3,4,6-8,11,12]$, polycaprolactone (PCL) $[1,3$, 6], polyurethane (PU) $[13,14]$, polyvinylpyrrolidone (PVP) [15], and polyvinyl alcohol (PVA) [1, 4, 6, 16]. Materials composed of these polymers display advanced mechanical properties if compared to natural polymers. The properties of wound healing materials can be modified by spinning biopolymers in combination with synthetic polymers to control the mechanical, degradation, and/or morphological characteristics of the porous fiber materials considering the needs of the individual patient [2].

Formulation of active wound dressing material could be achieved by structural control of electrospun nonwoven materials and efficient loading of drug substances into nano/ microfibers. Studies on manufacturing bicomponent chitosan/PLA hybrid nanofibrous materials and evaluation of their antibacterial properties have confirmed the adhesion of pathogenic bacteria S. aureus onto the surface of electrospun materials, which was considered a criterion for their applicability in manufacturing wound dressings. It has been shown that cross-linked electrospun nanofiber materials were efficient in inhibiting the growth of the Gram-positive bacteria $S$. aureus and the Gram-negative bacteria E. coli. Incorporation of chitosan and quaternized chitosan into electrospun materials increased the antiadhesive properties against $S$. aureus [8]. The incorporation of biologically active substances of ionic nature into PLA fibrous materials and polymer matrix composition can impact the spinning solution parameters and the fiber morphology [12].

Silver nanoparticles (AgNPs) demonstrate high antibacterial activity and provide anti-infective protection, and thus they can be considered as a suitable component for incorporation into biopolymeric electrospun membranes [1].

Multiple studies have demonstrated the antibacterial, antiviral, antifungal, antioxidant, anti-inflammatory, immunomodulating, antitumor, and anticancer properties of propolis, which depend on the chemical composition of its products $[10,11,13-15]$. Published data demonstrate the possibility of formulating electrospun polyvinylpyrrolidone nano/microfibers wound dressings that efficiently release propolis phenolic compounds [17].
The aim of this study was to formulate and investigate electrospun materials from biocompatible polylactic acid nano/microfibers containing biologically active compounds from propolis ethanolic extract (PEE). Antibacterial properties of electrospun materials were endowed by the addition of silver nanoparticles to the electrospinning solution.

\section{Materials and Methods}

2.1. Materials for Electrospinning Solution. Polylactic acid (PLA 6202D) was supplied from Nature Works LLS (USA) and contained 98\% L-lactide and 2\% D-lactide as declared by the producer. PLA solution (4\%) for electrospinning was prepared by dissolving PLA polymer in chloroform (SigmaAldrich, UK) and stirred for 5 hours by magnetic stirrer MSH (IKA-Werke GmbH \& Co. KG, Staufen, Germany). PLA nonwoven materials containing propolis phenolic components and AgNPs were produced by electrospinning process.

Propolis ethanolic extract (PEE) was produced by using $70 \%$ ethanol aqueous solution for extraction of raw propolis (UAB Medicata Filia, Lithuania) under mixing with a magnetic stirrer IKAMAG ${ }^{\circledR}$ C-MAG HS7 (IKA-Werke GmbH \& Co. KG, Staufen, Germany) for $1 \mathrm{~h}$ at room temperature. The stirrer rotation speed was $250 \mathrm{rpm}$. The ratio of raw propolis to extractive agent was 1:10. PEE was filtered through a filter paper with 20 to $25 \mu \mathrm{m}$ pores (DP 411, Albet ${ }^{\circledR}$ Filtration \& Separation Technology, Spain) and standardized by dilution to an appropriate concentration of total phenolic compounds (1504 or $1663 \mu \mathrm{g} / \mathrm{mL}$ ) [19]. The ranges of concentration of phenolic compounds were $180.4-206.4 \mu \mathrm{g} / \mathrm{mL}$ of vanillic acid, $31.3-48.8 \mu \mathrm{g} / \mathrm{mL}$ of caffeic acid, $307.1-344.5 \mu \mathrm{g} / \mathrm{mL}$ of vanillin, $571.4-637.4 \mu \mathrm{g} / \mathrm{mL}$ of $\mathrm{p}-$ coumaric acid, and $394.7-443.5 \mu \mathrm{g} / \mathrm{mL}$ of ferulic acid, thus indicating that $\mathrm{p}$-coumaric and ferulic acids and vanillin are dominating components in Lithuanian propolis.

AgNPs were incorporated into microfibers by admixing AgNPs colloidal solutions to the electrospun mixture. The colloidal solutions of AgNPs were produced by the addition of ethanolic $\mathrm{AgNO}_{3}$ to polyvinylpyrrolidone (PVP) solution. PVP was used as a reduction agent, anticoagulant, and stabilizer. The reaction proceeded at room temperature without stirring for 24 hours. Electrospun solutions contained $5 \mathrm{wt} \%$ of AgNPs colloidal solution and the quantity of AgNPs in the colloidal solution resulted in $1.16 \mathrm{wt} \%$ of $\mathrm{Ag}$ in electrospun microfibers.

During this study, nine types of solutions for electrospinning were prepared (Table 1).

2.2. Silver Nanoparticle Size Determination. Silver particle mean size was determined by applying dynamic light scattering technique which was performed using ZetaSizer Nano ZS particle size analyzer (Malvern, UK). Measurements were performed at $25^{\circ} \mathrm{C}$.

2.3. Determination of the Viscosity of Electrospun Solution. Viscosity of polymer solutions was determined by the funnel viscosimeter VZ-1 at room temperature. The time (s) in which 


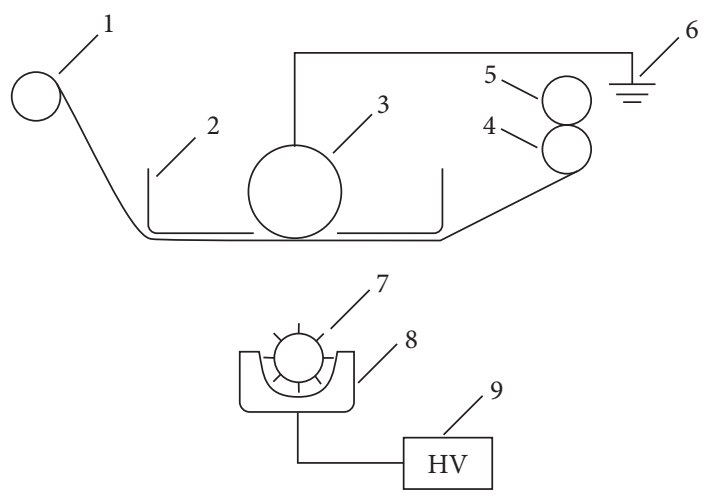

FIGURE 1: "Nanospider" electrospinning equipment. 1, 4, and 5: rollers of support material; 2: frame of grounded (6) electrode; 3: grounded electrode; 7: electrode with tines; 8: tray with polymer solution; 9: high voltage supply [18, 19].

TABLE 1: Concentration of electrospun PLA solutions.

\begin{tabular}{|c|c|}
\hline Sample code & Composition of electrospun solutions \\
\hline A & $\begin{array}{l}\text { PLA solution (concentration of PLA in solution } \\
\qquad C=4 \mathrm{wt} \%)\end{array}$ \\
\hline B & PLA with 10 wt $\%$ ethanol (PLA $C=4$ wt\%) \\
\hline $\mathrm{C}$ & PLA with 20 wt $\%$ ethanol (PLA $C=4 \mathrm{wt} \%$ ) \\
\hline $\mathrm{D}$ & PLA with 10 wt\% PEE (PLA C = 4 wt\%) \\
\hline $\mathrm{E}$ & PLA with 20 wt $\%$ PEE $($ PLA $C=4$ wt $\%)$ \\
\hline $\mathrm{F}$ & $\begin{array}{l}\text { PLA with } 5 \text { wt } \% \text { colloidal solution of AgNPs (PLA } \\
\qquad C=4 \mathrm{wt} \%)\end{array}$ \\
\hline G & $\begin{array}{l}\text { PLA with } 10 \mathrm{wt} \% \text { PEE and } 5 \mathrm{wt} \% \text { colloidal } \\
\text { solution of AgNPs (PLA C = 4 wt } \% \text { ) }\end{array}$ \\
\hline $\mathrm{H}$ & $\begin{array}{l}\text { PLA with } 20 \mathrm{wt} \% \text { PEE and } 5 \mathrm{wt} \% \text { colloidal } \\
\text { solution of AgNPs (PLA C = 4 wt } \% \text { ). }\end{array}$ \\
\hline
\end{tabular}

$100 \mathrm{~mL}$ of the spinning solution flowed down through the funnel with $5.4 \mathrm{~mm}$ diameter opening was determined.

2.4. Electrospinning Process. Nonwoven materials from microfibers were formed using "Nanospider ${ }^{\mathrm{TM}}$ " (Elmarco, Czech Republic) electrospinning equipment (Figure 1). Microfibers from PLA solution were formed at applied voltage $U=$ $50 \mathrm{kV}$, distance between electrodes $L=13 \mathrm{~cm}$, temperature of environment maintained at $T=20 \pm 2^{\circ} \mathrm{C}$, and air humidity $\varphi=$ $42 \pm 4 \%$.

2.5. Characterization of Electrospun Materials. The morphology of electrospun nonwoven materials was determined using scanning electron microscope (SEM) S-3400N (Hitachi, Japan). The diameter of microfibers was evaluated using SEM images and software NIS-Elements D (Nikon Corporation, Japan).

Fourier transform infrared spectroscopy (FT-IR) was used to determine possible interactions between functional groups of PEE compounds and PLA. FT-IR spectra of the fibers were obtained using FT-IR Spectrum GX spectrometer (PerkinElmer). About $1 \mathrm{mg}$ of the powdered sample was mixed with $200 \mathrm{mg}$ of potassium bromide (KBr) and vacuumpressed into a tablet. FT-IR spectra of the sample were recorded in the range from 4000 to $400 \mathrm{~cm}^{-1}$.

The surface wettability of the PLA and PLA/PEE microfibers was determined by measuring the contact angle in contact with distilled water. The measurements were performed using special display consisting of adjustable table, microsyringe, and video camera and analyzing the data with Motic Images Plus 2.0 software. Contact angle was measured immediately after application of a 20-microliter distilled water droplet on the nonwoven material surface. The results represent the mean of 5 measurements.

2.6. Release Studies of Silver Nanoparticles from Electrospun Microfibers In Vitro and Particle Size Determination. The precise amounts of microfibers (approx. $0.004 \mathrm{~g}$ ) were immersed into $20 \mathrm{~mL}$ of $10 \%$ acetonitrile in water (dissolution medium), which was stirred periodically using hotplate magnetic stirrer IKAMAG C-MAG HS7 (IKA-Werke GmbH \& Co. KG, Germany). An in vitro release study was performed at room temperature. $1 \mathrm{~mL}$ of acceptor medium was removed at 1,2 , $4,6,8$, and 24 hours' time points and replaced by the same volume of fresh dissolution medium. The mean particle size in the acceptor medium after release from microfibers was measured by applying a dynamic light scattering technique with a ZetaSizer Nano ZS particle size analyzer (Malvern, $\mathrm{UK})$. Measurements were performed at $25^{\circ} \mathrm{C}$.

2.7. Release Studies of Propolis Phenolic Acids from Electrospun Microfibers In Vitro. Samples of acceptor phase used in determination of released silver nanoparticles were filtered through polyvinylidene chloride filter, and chromatographic quantification of vanillin and vanillic, caffeic, p-coumaric, and ferulic acids was performed applying the earlier developed and validated method [17]. Propolis phenolic compounds (vanillic, caffeic, p-coumaric, and ferulic acids and vanillin) were quantified in propolis extracts and samples using Agilent 1260 Infinity Capillary LC (Agilent Technologies, Inc., Santa Clara, CA, USA) with Agilent diode array detector (DAD). The conditions of the applied validated HPLC method were as follows: C18 column $(150 \times 0.5 \mathrm{~mm}$, 
$5 \mu \mathrm{m}$ particle size), column temperature $25^{\circ} \mathrm{C}$, linear elution gradient from 1 to $21 \%$ of acetonitrile (solvent $\mathrm{A}$ ) in acetic acid $(0.5 \%, \mathrm{v} / \mathrm{v}$ ) in ultrapure water (solvent B) for $25 \mathrm{~min}$, flow rate $20 \mu \mathrm{L} / \mathrm{min}$, injected volume $0.2 \mu \mathrm{L}$, and detection of phenolic compounds performed at $290 \mathrm{~nm}$.

\subsection{The Antibacterial and Antifungal Activity Tests for Electrospun PLA Nonwoven Materials}

2.8.1. Antimicrobial Susceptibility Tests. The antibacterial and antifungal activity was performed in vitro using an agar diffusion method in Mueller-Hinton II agar medium (BBL, Cockeysville, USA). The antimicrobial activity of nonwoven materials from PLA microfibers with AgNPs was investigated in vitro in these standard bacterial cultures: Staphylococcus aureus ATCC 25923, Staphylococcus epidermidis ATCC 12228, Escherichia coli ATCC 25922, Pseudomonas aeruginosa ATCC 27853, Proteus mirabilis ATCC 12453, Bacillus cereus ATCC 11778, and fungal culture Candida albicans ATCC 10231.

2.8.2. Preparation of Standard Microorganism Cultures. Standard cultures of nonsporic bacteria Staphylococcus aureus, Staphylococcus epidermidis, Escherichia coli, Pseudomonas aeruginosa, and Proteus mirabilis were cultivated for 20-24 h at the temperature of $35^{\circ} \mathrm{C}$ in Mueller-Hinton agar medium (Mueller-Hinton II agar, BBL, Cockeysville, USA). A bacterial suspension was prepared from cultivated bacterial cultures in a physiological solution according to turbidity standard 0.5 McFarland.

Standard culture of sporic bacteria Bacillus cereus was cultivated for 7 days at the temperature of $35-37^{\circ} \mathrm{C}$ in MuellerHinton II agar medium. After the sporic bacteria culture had grown, it was washed away from the surface of the broth with sterile physiological solution and was heated for $30 \mathrm{~min}$ at the temperature of $70^{\circ} \mathrm{C}$ and diluted until the concentration of spores in $1 \mathrm{~mL}$ ranged from $10 \times 10^{6}$ to $100 \times 10^{6}$. Sporic suspension can be kept for a long time at temperature below $4^{\circ} \mathrm{C}$.

The standard fungal culture Candida albicans was cultivated for $20-24 \mathrm{~h}$ at $30^{\circ} \mathrm{C}$ in Mueller-Hinton II agar medium (Mueller-Hinton II agar, BBL, Cockeysville, USA). A fungal suspension was prepared from cultivated fungal cultures in a physiological solution according to the turbidity standard 0.5 McFarland [18].

2.8.3. Preparation of Investigative Compounds for the Antimicrobial Activity. Samples from nonwoven materials from PLA microfibers without and with AgNPs were cut into small $8 \mathrm{~mm} \times 10 \mathrm{~mm}$ size sheets. All samples were sterilized by ultraviolet rays. Microbial cultures (cell suspension of $1 \times$ $10^{8}$ cells $/ \mathrm{mL}$ ) were inoculated with a sterile swab onto the surface of Mueller-Hinton agar in a Petri dish. Later on, the sterilized nonwoven materials from PLA microfibers with AgNPs samples were gently placed on Mueller-Hinton agar with microbial culture sown in sterile conditions. Samples in Mueller-Hinton agar were incubated at $36^{\circ} \mathrm{C}$ for $24 \mathrm{~h}$ (for bacteria) and at $30^{\circ} \mathrm{C}$ for $24 \mathrm{~h}$ (for fungi). Samples from nonwoven materials of PLA microfibers with AgNPs antimicrobial activity were determined by the sterile area of the sample $[17,18]$.

\subsection{Evaluation of Cytotoxicity of Electrospun Microfibers}

2.9.1. Cell Lines and Cell Culture. The immortalized human keratinocyte cell line, HaCaT cells, was obtained from Cell Lines Service GmbH (Germany). The cells were seeded and grown in culture flasks with DMEM containing 10\% fetal bovine serum (FBS) and $100 \mathrm{U} / \mathrm{mL}$ penicillin and $100 \mu \mathrm{g} / \mathrm{mL}$ streptomycin. $\mathrm{HaCaT}$ cells were cultured at $37^{\circ} \mathrm{C}$ in humidified conditions with $5 \% \mathrm{CO}_{2}$.

2.9.2. Measurement of Cell Viability. The cytotoxicity of microfiber materials was evaluated to assess their biological compatibility. Cell viability was assessed by MTT method [20]. The cells were seeded onto 96-well plates at a density of 20,000 cells/well and incubated for $24 \mathrm{~h}$. After incubation, cells were treated with different formulations: propolis containing electrospun microfibers and microfibers without propolis. Surface area (single side) of all microfiber materials applied on the cells in each well was $36.30 \mathrm{~mm}^{2}$. All these samples were sterilized under an ultraviolet lamp for $1 \mathrm{~h}$ before the treatment of cells [21, 22]. After 24h, DMEM medium and microfibers materials were removed and cells were washed twice with HBSS (100 $\mu \mathrm{L} /$ well). After washing, $180 \mu \mathrm{L} /$ well HBSS and $20 \mu \mathrm{L} /$ well MTT $(5 \mathrm{mg} / \mathrm{mL})$ dye were added to each well, and cells were incubated for $2 \mathrm{~h}$ at $37^{\circ} \mathrm{C}$ in humidified conditions with $5 \% \mathrm{CO}_{2}$. Afterwards, the solution was removed and DMSO (100 $\mu \mathrm{L} /$ well) was added to dissolve formazan crystals. Absorption was measured at $550 \mathrm{~nm}$ and $620 \mathrm{~nm}$ wavelength using microplate spectrophotometer (Thermo Scientific Multiscan FC, USA). The results of cellular viability were expressed as percentage of untreated control cells. The viability of nontreated control cells was arbitrarily defined as $100 \%$.

2.9.3. Assessment of Cell Count and Cell Death Using Hoechst and Propidium Iodide Dyes. Cell count was performed using Hoechst 33258 and propidium iodide dyes. The cells were seeded onto 96 -well plates at a density of 20,000 cells/well and incubated for $24 \mathrm{~h}$. After $24 \mathrm{~h}$, microfiber samples were added to the medium for $24 \mathrm{~h}$. After treatment, Hoechst 33258 and propidium iodide dyes were added to the culture medium and incubated for $15 \mathrm{~min}$. Viable, apoptotic, and necrotic cells were counted under fluorescence microscope (Olympus IX71S1F-3, USA).

2.10. Statistical Analysis. Statistical analysis of experimental data was performed using SPSS software (version 19.0) and Microsoft Office Excel 2013. The significance of differences in test results was assessed by using Student's $t$-test. A statistically significant difference was determined when $P<$ 0.05 . 
TABLE 2: Viscosity of PLA solutions and diameter of electrospun PLA microfibers.

\begin{tabular}{|c|c|c|c|}
\hline Sample code & Composition of electrospun solutions & $\begin{array}{l}\text { Viscosity } \\
\bar{\eta} \pm \Delta^{*}, \mathrm{~s}\end{array}$ & $\begin{array}{c}\text { Average diameter } \\
\text { of electrospun PLA } \\
\text { microfibers, } \\
n m \pm \Delta^{*}\end{array}$ \\
\hline A & Pure PLA solution (concentration of PLA in solution $C=4 \mathrm{wt} \%$ ) & $7,3 \pm 0.03$ & $168 \pm 29$ \\
\hline B & PLA with $10 \mathrm{wt} \%$ ethanol (PLA $C=4$ wt $\%$ ) & $6,5 \pm 0.5$ & $318 \pm 40$ \\
\hline $\mathrm{C}$ & PLA with $20 \mathrm{wt} \%$ ethanol (PLA $C=4 \mathrm{wt} \%)$ & $6,3 \pm 0.3$ & $370 \pm 30$ \\
\hline $\mathrm{D}$ & PLA with 10 wt\% PEE (PLA C = 4 wt\%) & $7,0 \pm 0.3$ & $282 \pm 25$ \\
\hline $\mathrm{E}$ & PLA with 20 wt $\%$ PEE (PLA $C=4$ wt\%) & $6,8 \pm 0.3$ & $371 \pm 25$ \\
\hline $\mathrm{F}$ & PLA with 5 wt $\%$ colloidal solution of AgNPs (PLA C = 4 wt $\%)$ & $7,1 \pm 0.4$ & $254 \pm 25$ \\
\hline G & PLA with $10 \mathrm{wt} \%$ PEE and $5 \mathrm{wt} \%$ colloidal solution of AgNPs (PLA C $=4 \mathrm{wt} \%$ ) & $7,0 \pm 0.1$ & $280 \pm 29$ \\
\hline $\mathrm{H}$ & PLA with $20 \mathrm{wt} \%$ PEE and $5 \mathrm{wt} \%$ colloidal solution of AgNPs (PLA C $=4 \mathrm{wt} \%$ ). & $7,1 \pm 0.3$ & - \\
\hline
\end{tabular}

${ }^{*}$ The absolute error.

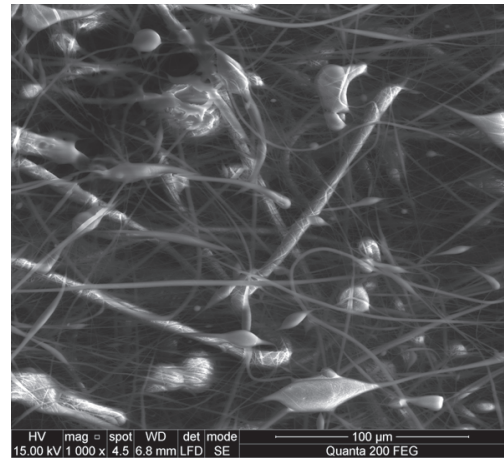

(A)

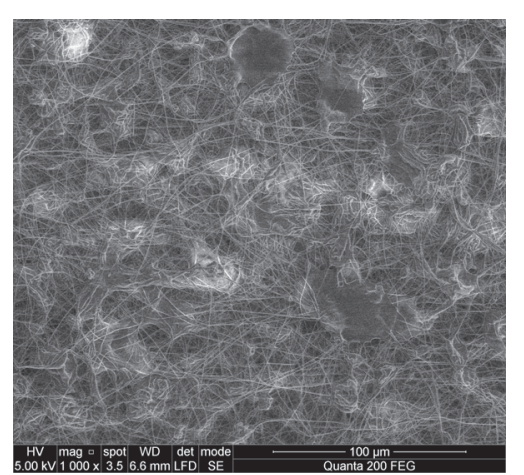

(B)

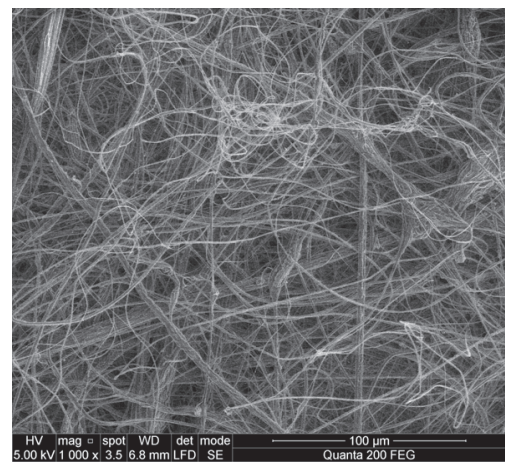

(C)

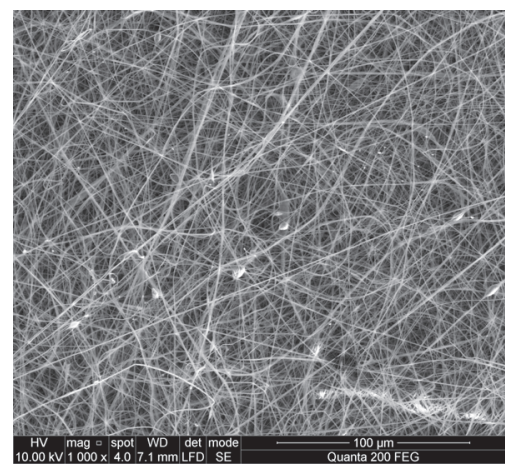

(D)

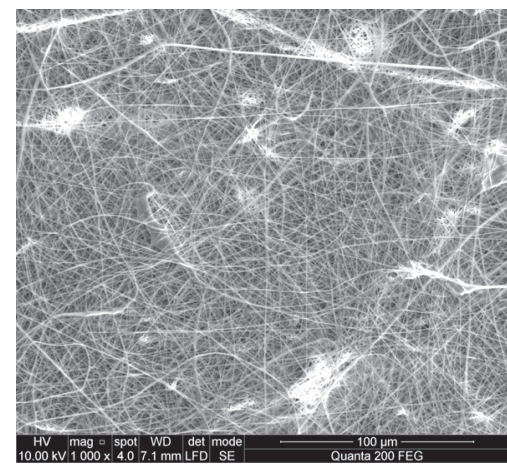

(E)

FIGURE 2: SEM images (scale: $100 \mu \mathrm{m}$, magnification: 1000x) of electrospun PLA materials. (A) PLA solution (4 wt\%), (B) PLA solution (4 wt \%) containing $10 \mathrm{wt} \%$ ethanol, (C) PLA solution (4 wt\%) containing $20 \mathrm{wt} \%$ ethanol, (D) PLA solution (4 wt\%) containing $10 \mathrm{wt} \% \mathrm{PEE}$, and (E) PLA solution (4 wt\%) containing $20 \mathrm{wt} \%$ PEE.

\section{Results and Discussion}

The effect of AgNPs, PEE, and ethanol presence in the electrospun solutions was evaluated by analyzing the morphology and determining characteristics of electrospun PLA.

The viscosity of the analyzed polymer solutions with different additional materials is presented in Table 2.

According to the data presented in Table 2, it is evident that addition of ethanol up to $20 \%$, PEE up to $20 \%$, and
AgNPs up to $10 \%$ had a minor effect on the decrease of viscosity of solutions used in electrospinning.

Figures 2 and 3 present the morphology of electrospun nonwoven materials from PLA with pure ethanol and PEE microfibers.

SEM images presented reliable evidence of the quality of the produced microfibers (Figures 2 and 3). It was identified that inclusion of ethanol and PEE in PLA polymer solution resulted in an improved electrospinning process and resulted 


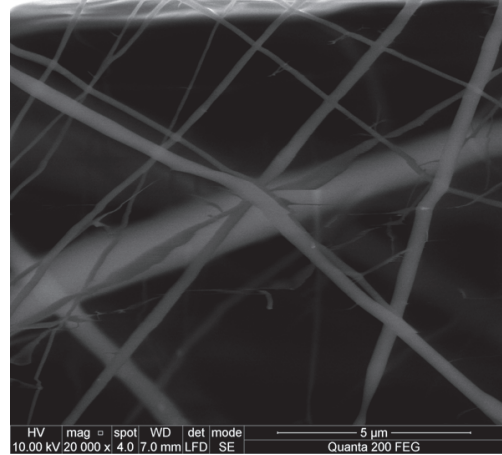

(A)

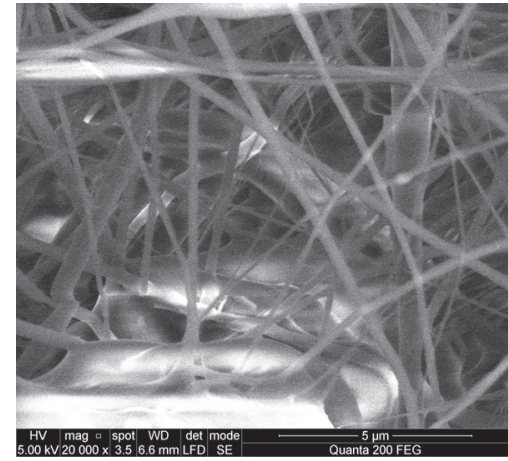

(B)

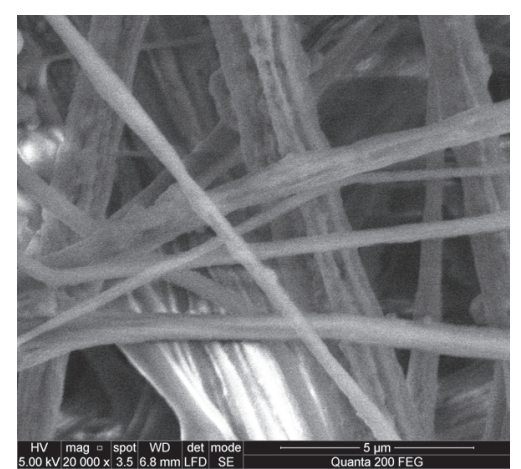

(C)

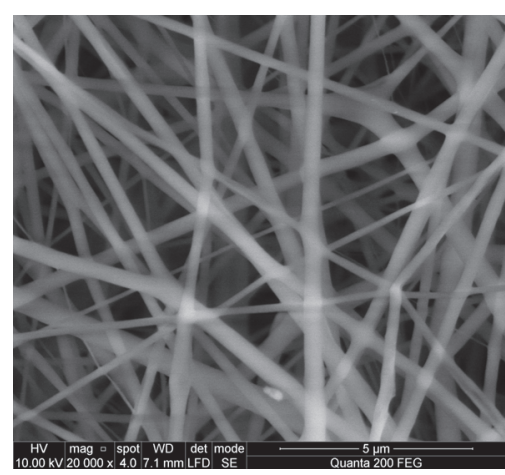

(D)

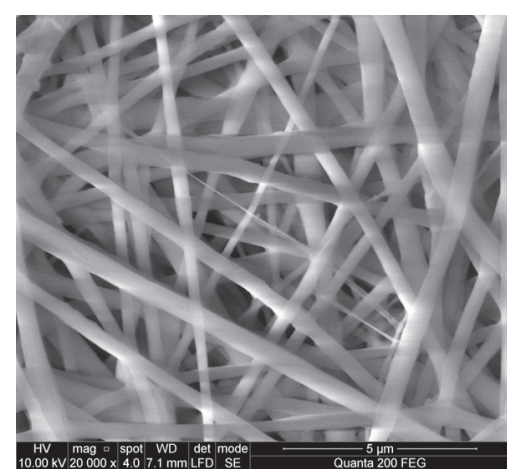

(E)

Figure 3: SEM images (scale: $5 \mu \mathrm{m}$, magnification: 20,000x) of electrospun PLA materials: (A) PLA solution (4 wt\%), (B) PLA solution (4 wt\%) containing $10 \mathrm{wt} \%$ ethanol, (C) PLA solution (4 wt\%) containing $20 \mathrm{wt} \%$ ethanol, (D) PLA solution (4 wt $\%$ ) containing $10 \mathrm{wt} \%$ PEE, and (E) PLA solution (4 wt\%) containing $20 \mathrm{wt} \%$ PEE.

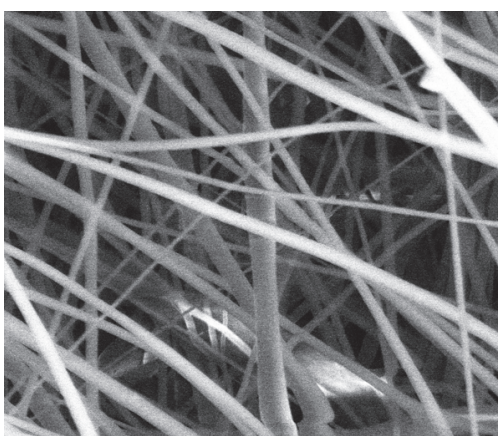

(F)

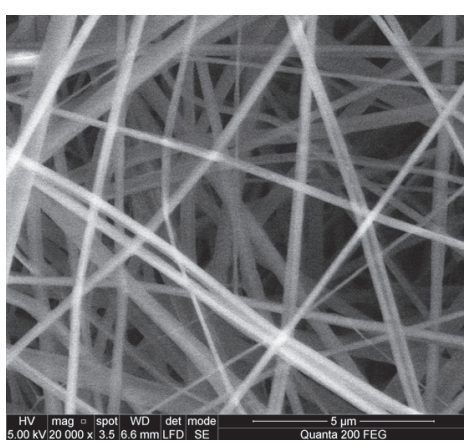

$(\mathrm{G})$

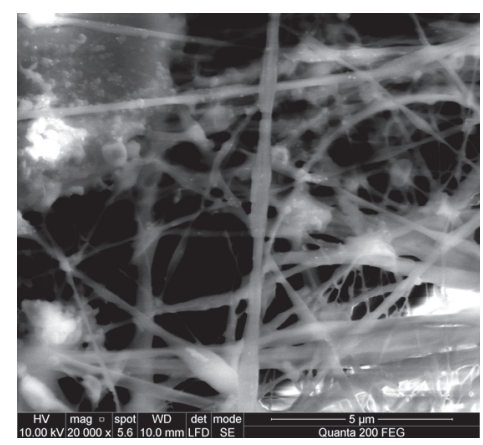

$(\mathrm{H})$

FIGURE 4: SEM images (scale: $5 \mu \mathrm{m}$, magnification: 20,000x) of electrospun PLA materials produced using (F) PLA (4 wt\%) containing suspension of AgNPs (5 wt\%), (G) PLA (4 wt\%) containing PEE (10 wt\%) and AgNPs (5 wt\%), and (H) PLA (4 wt\%) containing PEE (20 wt \%) and AgNPs (5 wt\%).

in the formation of a denser electrospun nonwoven material from PLA microfibers. Comparison of ethanol and PEE effects on the morphology of produced PLA microfibers confirmed that uniform PLA microfibers were formed in the presence of PEE. Although PLA polymer has limited solubility in ethanol, its presence in electrospun solutions did not impair the electrospinning process. These results correlate with results presented by Ikeuchi and coauthors [23] when uniform electrospun PLA microfibers from PLA in chloroform (PLA concentration 2\%) solution with 20\% ethanol have been produced.

The morphologies of electrospun nonwoven materials from PLA polymer solutions containing AgNPs and different amounts of PEE are presented in Figure 4.

The presence of AgNPs in the PLA solution improved the electrospinning process results when comparing sample A (Figure 3) with sample F (Figure 4). Similar results were obtained after addition of $\mathrm{AgNO}_{3}$ in $\mathrm{PLA} /$ chitosan 


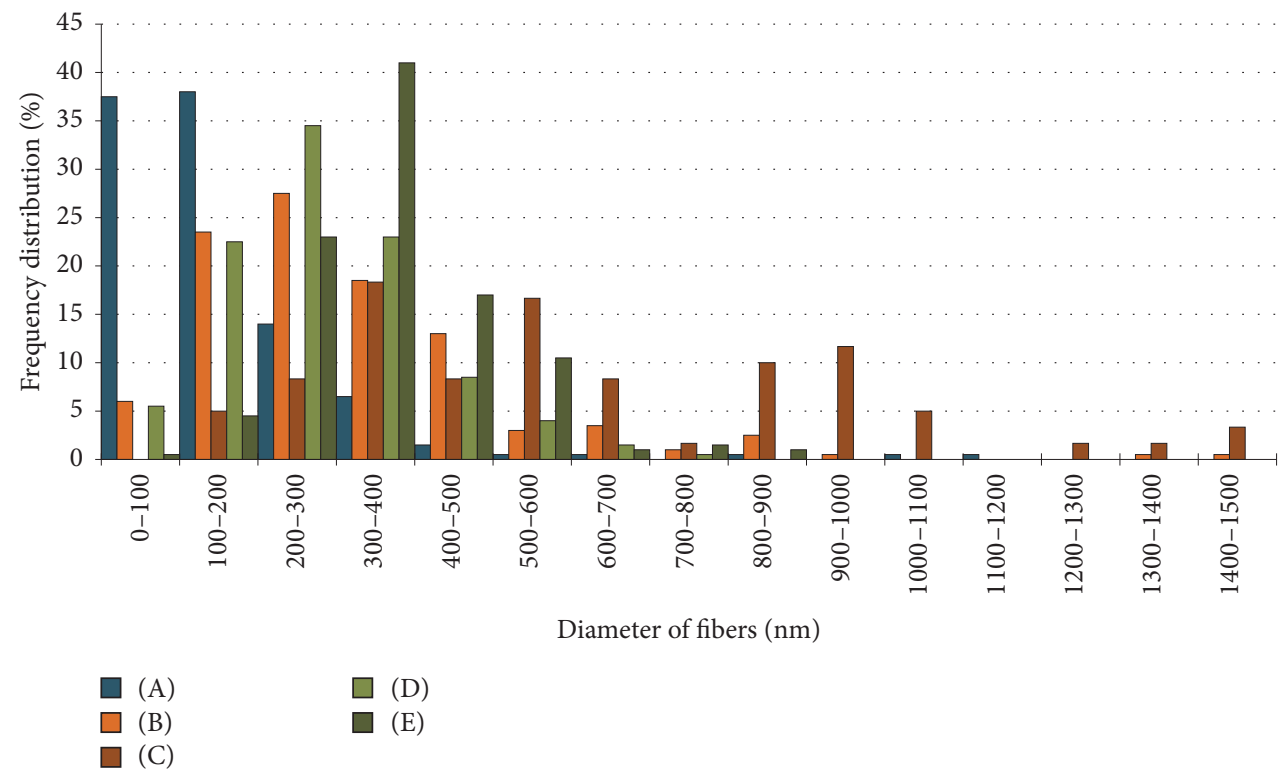

FIgURE 5: The diameter distribution of PLA microfibers electrospun from PLA polymer with (A) PLA solution (4 wt\%), (B) PLA solution (4 wt\%) containing $10 \mathrm{wt} \%$ ethanol, (C) PLA solution (4 wt\%) containing $20 \mathrm{wt} \%$ ethanol, (D) PLA solution (4 wt $\%$ ) containing $10 \mathrm{wt} \%$ PEE, (E) PLA solution (4 wt\%) containing $20 \mathrm{wt} \%$ PEE, and (F) PLA solution (4wt\%) containing suspension of AgNPs (5 wt $\%)$.

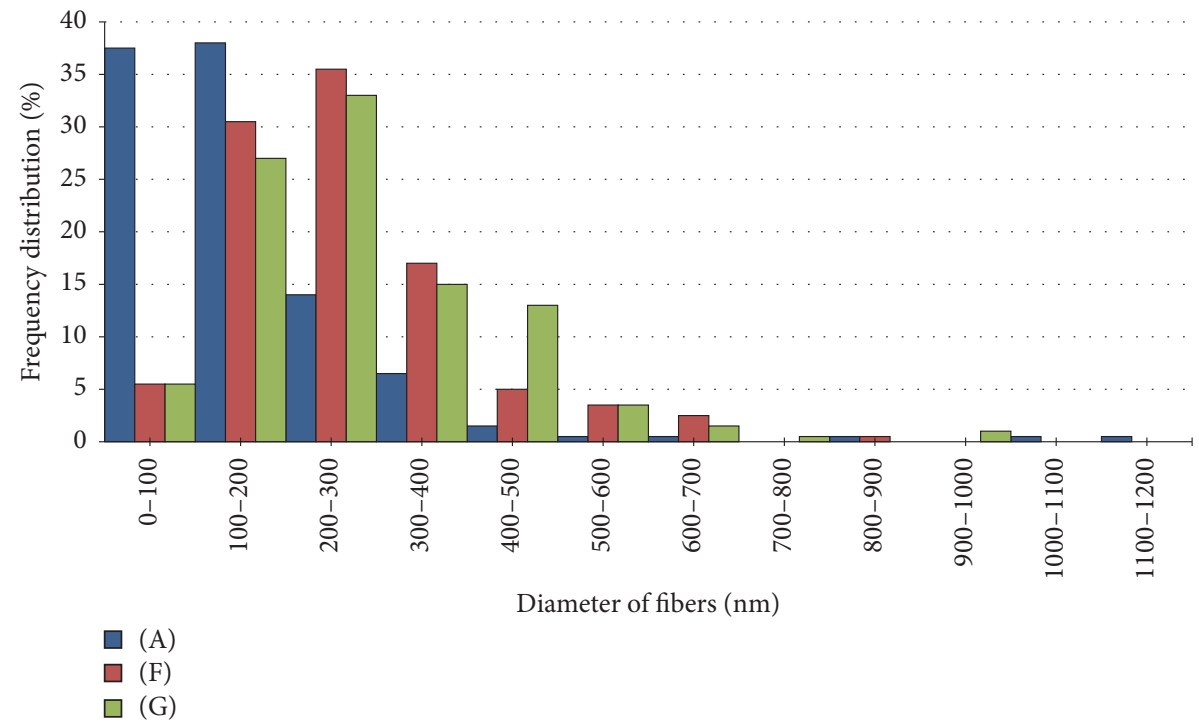

Figure 6: The distribution of diameter of PLA microfibers electrospun from (F) PLA solution (4 wt\%) containing suspension of AgNPs (5 wt\%) and (G) PLA solution (4 wt\%) containing $10 \mathrm{wt} \%$ PEE and suspension of AgNPs (5 wt $\%$ ).

solution [24]. More numerous defects were determined in the produced nonwoven material when PLA solution containing AgNP and $20 \mathrm{wt} \%$ of PEE for electrospinning was used (Figure 4, sample H) if compared to PLA solution with AgNP and $10 \mathrm{wt} \%$ of PEE (Figure 4, sample G). The electrospinning process was improved by the presence of ethanol and AgNP in PLA solution. Only in the case when 5\% of AgNP and 20\% of PEE in PLA solution were used has the occurrence of defects in electrospun material been determined. Such results may be caused by increased instability of electrospun jet of solution.
The electrospinning process could be evaluated by the thickness of the produced microfibers. The distribution of electrospun PLA microfibers mean diameters is presented in Figures 5 and 6 . The diameter distribution patterns demonstrate that thinner microfibers (diameter up to $200 \mathrm{~nm}$ ) resulted from PLA solutions containing no added AgNP and/or PEE (Figure 4, A). It should be mentioned that the density of the material was the smallest in this case.

The increase of the ethanol amount in the electrospun solution resulted in increased diameter of the fibers. When 
TABLE 3: Mean particle size and polydispersity index of Ag nanoparticles in acceptor medium.

\begin{tabular}{lcccccc}
\hline \multirow{2}{*}{ Sample } & \multicolumn{5}{c}{ Duration, $\mathrm{h}$} \\
\multicolumn{1}{c}{1} & 2 & 4 & 6 & 8 & 24 \\
\hline F & & & & & \\
$\quad$ Particle size, nm & $215.1 \pm 16.20$ & $180.4 \pm 8.896$ & $184.3 \pm 7.460$ & $199.7 \pm 11.55$ & $202.4 \pm 12.21$ & $244.0 \pm 28.13$ \\
$\quad$ PDI & $0.446 \pm 0.088$ & $0.422 \pm 0.052$ & $0.429 \pm 0.043$ & $0.369 \pm 0.036$ & $0.382 \pm 0.043$ & $0.365 \pm 0.047$ \\
G & & & & & \\
$\quad$ Particle size, nm & $47.18 \pm 3.181$ & $62.57 \pm 4.175$ & $43.64 \pm 1.305$ & $42.03 \pm 0.561$ & $44.15 \pm 0.260$ & $55.81 \pm 1.735$ \\
$\quad$ PDI & $0.456 \pm 0.066$ & $0.135 \pm 0.017$ & $0.513 \pm 0.030$ & $0.527 \pm 0.023$ & $0.497 \pm 0.032$ & $0.186 \pm 0.023$ \\
\hline
\end{tabular}

electrospun PLA solution contained $10 \%$ ethanol, $30 \%$ of the fibers had a diameter up to $200 \mathrm{~nm}$, but increasing the amount of ethanol to $20 \%$ resulted in $5 \%$ of the fibers having a diameter up to $200 \mathrm{~nm}$. Similar changes in the diameter of produced fibers were demonstrated when the quantity of PEE was increased from $10 \%$ to $20 \%$; the quantity of the fibers with a diameter up to $200 \mathrm{~nm}$ decreased from $28 \%$ to $5 \%$. The results of average diameter distribution for PLA microfibers are presented in Table 2. Similar results were demonstrated when microfibers were produced from PU and PVP with propolis. The increase of propolis amount in PU [13] and PVP [15] polymer solutions caused a similar increase of diameter of electrospun fibers. The results suggest that incorporation of charged compounds in the electrospinning solution can generally improve the electrospinning process and it allows forming thick nonwoven materials. The amount of additional materials in PLA polymer solution affects the morphology of the produced microfibers. The data presented in Figure 6 demonstrate that inclusion of AgNPs and PEE causes the formation of thicker PLA microfibers with dominating mean diameter above $200 \mathrm{~nm}$.

From PLA/AgNPs (sample F) polymer solution, 36\% of fibers with a diameter up to $200 \mathrm{~nm}$ were measured, and from PLA/10 wt \% propolis/ethanol solution $32.5 \%$ of fibers with a diameter up to $200 \mathrm{~nm}$ were measured (Figure 6).

FT-IR spectra were used to confirm the presence of functional groups of PEE compounds in PLA microfibers. Thus, the FT-IR spectra of PLA (A), PLA/10 wt\% PEE (D), and PLA/10 wt $\%$ PEE containing $5 \mathrm{wt} \%$ AgNPs colloidal solution (G) were recorded (Figure 7). The peaks at 1741, 1180, and $1084 \mathrm{~cm}^{-1}$ in FT-IR spectra are specific for PLA. Addition of PEE to PLA microfibers resulted in the appearance of bands at 2923 and $2851 \mathrm{~cm}^{-1}$. The peaks at 1515, 1271, and $1167 \mathrm{~cm}^{-1}$ were identified as specific for PEE containing microfibers with and without AgNPs.

Wettability of electrospun microfibers was evaluated by determining the contact angle [25]. The contact angles of nonwoven materials in contact with water provide information on surface hydrophobicity of the formed microfibers. The change in the wetting angles can also indicate the effect of PEE on hydrophilicity of nonwoven materials. Water contact angles for PLA, PLA/10 wt\% PEE, and PLA/10 wt\% PEE containing $5 \mathrm{wt} \%$ of AgNPs colloidal solution were $36.2^{\circ} \pm 18$, $30^{\circ} \pm 16$, and $22^{\circ} \pm 10$, respectively. Results demonstrated that addition of PEE caused the decrease of water contact

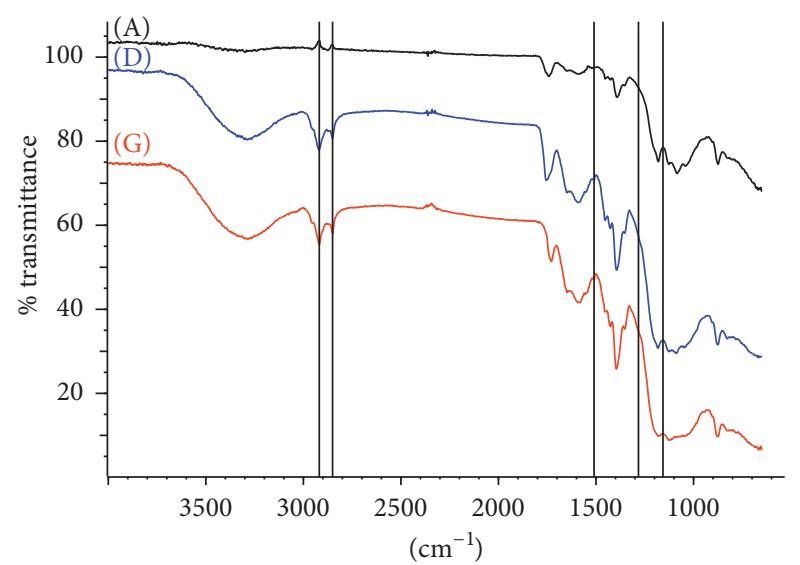

FIGURE 7: FT-IR spectra of microfibers, produced by electrospinning of (A) PLA solution (4 wt\%), (D) PLA solution (4 wt\%) containing $10 \mathrm{wt} \%$ PEE, and (G) PLA solution (4 wt\%) containing $10 \mathrm{wt} \%$ PEE and $5 \mathrm{wt} \%$ AgNPs colloidal solution.

angles, thus indicating higher hydrophilicity of PLA/PEE nonwoven materials if compared to PLA microfibers.

Analysis of the release of phenolic compounds from electrospun PLA microfibers demonstrated that release of propolis phenolic acids was below limits of quantification after 1 hour of testing. After 24 hours, only p-coumaric acid was quantified while testing the release of phenolic acids from PLA with $10 \mathrm{wt} \%$ propolis/ethanol microfibers (sample G) and was $0.347 \mu \mathrm{g} / \mathrm{mL}$.

Determination of AgNPs mean particles size showed a regular increase of measured diameter. Data on mean particle size and polydispersity index of AgNPs in dissolution medium after immersion of microfiber mats are presented in Table 3.

The presence of Ag nanoparticles in acceptor media was determined at the first sampling point of 1 hour, and the mean size of the particles was 47.18 and $215.1 \mathrm{~nm}$ for PLA with $10 \mathrm{wt} \%$ PEE and $5 \mathrm{wt} \%$ suspension of AgNPs and PLA with $5 \mathrm{wt} \%$ suspension of AgNPs, respectively. The presence of PEE in microfibers resulted in smaller AgNPs released to acceptor media; thus, it could result in different biological activity profiles of microfibers when applied to biological systems. The mean particle size of AgNPs was constantly increasing while the polydispersity index was decreasing, 
TABLE 4: Antimicrobial activity of electrospun solutions and microfiber materials.

\begin{tabular}{|c|c|c|c|c|c|c|c|c|c|}
\hline \multirow{2}{*}{ Number } & \multirow{2}{*}{$\begin{array}{l}\text { Standard strains of } \\
\text { microorganisms }\end{array}$} & \multicolumn{8}{|c|}{ Nonwoven materials } \\
\hline & & A & B & $\mathrm{C}$ & $\mathrm{D}$ & $\mathrm{E}$ & $\mathrm{F}$ & G & $\mathrm{H}$ \\
\hline (1) & $\begin{array}{c}\text { Staphylococcus aureus } \\
\text { ATCC } 25923\end{array}$ & - & - & - & - & - & + & + & + \\
\hline (2) & $\begin{array}{c}\text { Klebsiella pneumoniae } \\
\text { ATCC } 13883\end{array}$ & - & - & - & - & - & + & + & + \\
\hline (3) & $\begin{array}{c}\text { Escherichia coli } \\
\text { ATCC } 25922\end{array}$ & - & - & - & - & - & + & + & + \\
\hline (4) & $\begin{array}{c}\text { Pseudomonas } \\
\text { aeruginosa } \\
\text { ATCC } 27853\end{array}$ & - & - & - & - & - & + & + & + \\
\hline (5) & $\begin{array}{l}\text { Proteus vulgaris } \\
\quad \text { ATCC } 8427\end{array}$ & - & - & - & - & - & + & + & + \\
\hline (6) & $\begin{array}{c}\text { Bacillus cereus } \\
\text { ATCC } 11778\end{array}$ & - & - & - & - & - & + & + & + \\
\hline (7) & $\begin{array}{l}\text { Candida albicans } \\
\text { ATCC } 10231\end{array}$ & - & - & - & - & - & + & + & + \\
\hline
\end{tabular}

-: no antibacterial activity determined; +: antibacterial activity determined.

indicating increasing homogeneity of the samples. Generally, this could be explained by the formation of agglomerates of AgNPs in the presence of increasing total number of AgNPs in liquid phase.

All samples were tested using prokaryotic microorganisms: Staphylococcus aureus ATCC 25923, Staphylococcus epidermidis ATCC 12228, Escherichia coli ATCC 25922, Pseudomonas aeruginosa ATCC 27853, Proteus mirabilis ATCC 12453, Bacillus cereus ATCC 11778, and eukaryotic microorganism fungal culture Candida albicans ATCC 10231. Staphylococcus aureus ATCC 25923 and Staphylococcus epidermidis ATCC 12228 are Gram-positive bacteria that have a cell wall of thick layer of peptidoglycan. Escherichia coli ATCC 25922, Pseudomonas aeruginosa ATCC 27853, and Proteus mirabilis ATCC 12453 are Gram-negative bacteria with two layers of cell wall. Bacillus cereus ATCC 8035 is a spore-forming bacterium. Characteristics of these microorganisms suggest that antimicrobial activity of the tested preparations may vary. The results of antimicrobial activity showed that nonwoven materials from PLA microfibers with AgNPs and PEE (samples F, G, and $\mathrm{H}$ ) can be characterized as demonstrating antimicrobial and antifungal activity (Table 4).

Samples without AgNPs did not show significant antibacterial and/or antifungal properties, and this could be attributed to low quantities of PEE in the electrospun solution. The highest antimicrobial activity was observed for nonwoven materials from PLA microfibers containing AgNPs (samples F, G, and H) against Gram-negative bacteria, Pseudomonas aeruginosa, and Gram-positive bacteria, Staphylococcus aureus. The nonwoven material of PLA microfibers with AgNPs effectively inhibits spore-forming bacteria Bacillus cereus and fungi Candida albicans growth.

Evaluation of cytotoxicity of electrospun PLA microfibers with PEE could provide insights into the possible application of microfiber materials in formulating products designed for topical application on the wounds with the aim of increasing

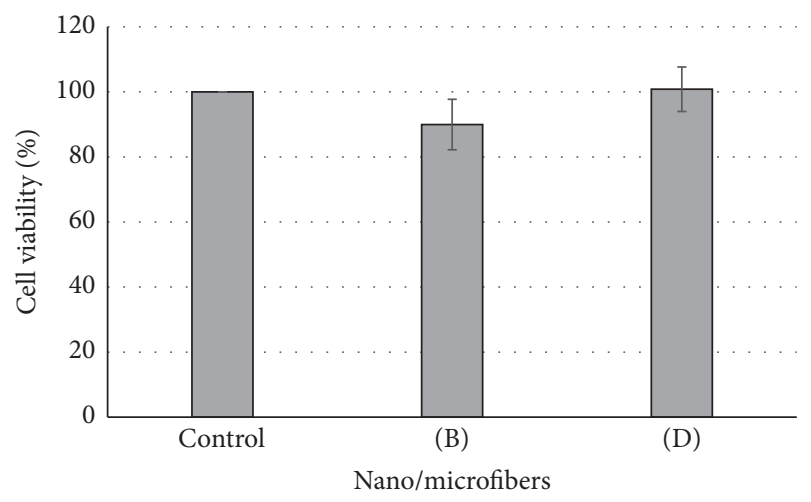

FIGURE 8: Cell viability in the presence of experimental formulations of electrospun microfibers. Electrospun PLA microfibers produced from a solution containing 10\% ethanol (B) and $10 \mathrm{wt} \%$ PEE (D).

wound healing rate and providing protection from potential external infections. Though the presence of propolis ethanolic extract has demonstrated absence of any antibacterial and antifungal effect of electrospun PLA microfibers, it seemed reasonable to expect that the presence of propolis components could affect cytotoxicity of electrospun microfibers. The suitability of microfiber materials for cell cultivation and the absence of cytotoxicity should support the possibility of developing wound healing supporting products based on electrospun microfiber materials as the ability of the product to preserve viability of the cells is of critical importance. The viability of the cells was evaluated by determining the fraction of the viable $\mathrm{HaCaT}$ cells in the presence of microfiber materials containing propolis extract (Figure 8).

The results of $\mathrm{HaCaT}$ cell viability determination demonstrated a statistically significant $10 \%$ decrease in the number of viable cells in the presence of PLA microfibers with $10 \%$ ethanol. No change in the number of viable cells was 


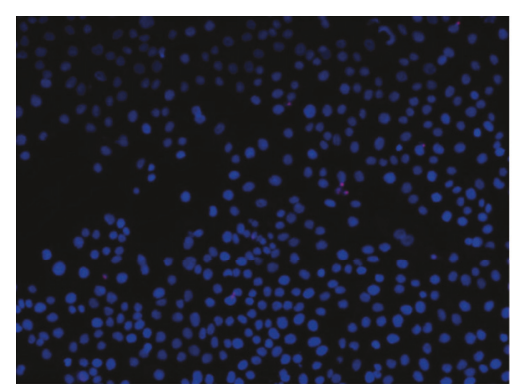

Control

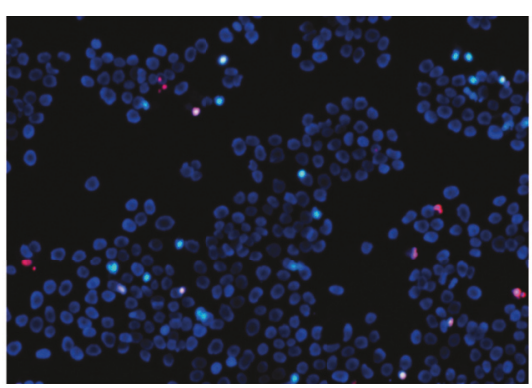

(B)

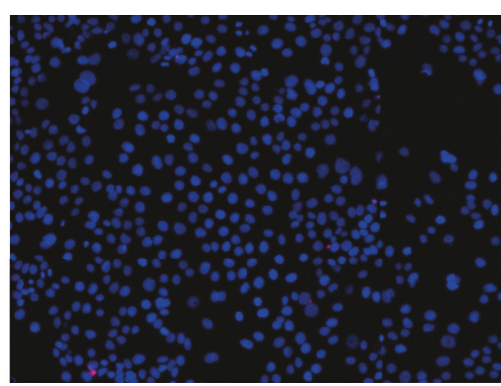

(D)

Figure 9: Typical images of HaCaT cell fluorescence after incubation with microfibers: control cells; (B) electrospun PLA microfibers produced from solution containing 10\% ethanol and (D) electrospun PLA microfibers produced from solution containing $10 \mathrm{wt} \%$ PEE.

determined when HaCaT cells have been incubated with PLA microfibers containing $10 \mathrm{wt} \% \mathrm{PEE}$, thus indicating the ability of microfiber materials with biologically active compound propolis to maintain viability of $\mathrm{HaCaT}$ cells.

Effects of microfibers on proliferation of $\mathrm{HaCaT}$ cells were evaluated by fluorescence measurement after incubation with Hoechst 33258 and propidium iodide dyes (Figure 9).

The results demonstrated a decrease of viable cell number when $\mathrm{HaCaT}$ cells were treated for $24 \mathrm{~h}$ with electrospun PLA microfibers produced from a solution containing $10 \%$ ethanol (Figure 9, B). Cell death by apoptosis (approx. 5\%) and by necrosis (approx. 3.5\%) has been determined. Treatment of cells with electrospun PLA microfibers produced from a solution containing $10 \mathrm{wt} \%$ PEE (Figure 8, D) resulted in an increased number of viable cells after $24 \mathrm{~h}$ incubation if compared to control. The results of cell viability evaluation correlate with the results obtained by MTT method and identify apoptosis as a predominant route of cell death.

\section{Conclusions}

Development of PLA based microfiber manufacturing methods and inclusion of PEE and AgNPs confirmed the possibility of modifying the properties of the resulting product, thus indicating different possible areas for application. The effect of ethanol presence in solution for electrospinning demonstrated how significantly the parameters of the produced microfibers can be affected. Also, the strong evidence of the AgNPs antibacterial and antifungal activity has been confirmed and it could be explained by the determined release of AgNPs from microfibers during biopharmaceutical characterization. On the contrary, only trace quantities of propolis phenolic acids were released from PLA based microfibers. But this may be of value in further development of propolis products containing microfibers as their ability to preserve the viability of keratinocytes was demonstrated by in vitro testing.

\section{Conflicts of Interest}

The authors declare that there are no conflicts of interest.

\section{Acknowledgments}

This research was funded by a grant from the Research Council of Lithuania (no. MIP-020/2014).

\section{References}

[1] P. Zahedi, I. Rezaeian, S.-O. Ranaei-Siadat, S.-H. Jafari, and P. Supaphol, "A review on wound dressings with an emphasis on electrospun nanofibrous polymeric bandages," Polymers for Advanced Technologies, vol. 21, no. 2, pp. 77-95, 2010.

[2] K. A. Rieger, N. P. Birch, and J. D. Schiffman, "Designing electrospun nanofiber mats to promote wound healing-a review," Journal of Materials Chemistry B, vol. 1, no. 36, pp. 4531-4541, 2013.

[3] P. Zahedi, Z. Karami, I. Rezaeian et al., "Preparation and performance evaluation of tetracycline hydrochloride loaded wound dressing mats based on electrospun nanofibrous poly(lactic acid)/poly( $\epsilon$-caprolactone) blends," Journal of Applied Polymer Science, vol. 124, no. 5, pp. 4174-4183, 2012.

[4] J. Wang and W. Vermerris, "Antimicrobial nanomaterials derived from natural products-a review," Materials, vol. 9, no. 4, article 255, 19 pages, 2016.

[5] A. Andukuri, M. Kushwaha, A. Tambralli et al., "A hybrid biomimetic nanomatrix composed of electrospun polycaprolactone and bioactive peptide amphiphiles for cardiovascular implants," Acta Biomaterialia, vol. 7, no. 1, pp. 225-233, 2011.

[6] V. Andreu, G. Mendoza, M. Arruebo, and S. Irusta, "Smart dressings based on nanostructured fibers containing natural origin antimicrobial, anti-inflammatory, and regenerative compounds," Materials, vol. 8, no. 8, pp. 5154-5193, 2015.

[7] S.-Y. Gu, Z.-M. Wang, J. Ren, and C.-Y. Zhang, "Electrospinning of gelatin and gelatin/poly(l-lactide) blend and its characteristics for wound dressing," Materials Science and Engineering C, vol. 29, no. 6, pp. 1822-1828, 2009.

[8] M. Ignatova, N. Manolova, N. Markova, and I. Rashkov, "Electrospun non-woven nanofibrous hybrid mats based on chitosan and PLA for wound-dressing applications," Macromolecular Bioscience, vol. 9, no. 1, pp. 102-111, 2009.

[9] Z.-X. Cai, X.-M. Mo, K.-H. Zhang et al., "Fabrication of chitosan/silk fibroin composite nanofibers for Wound-dressing Applications," International Journal of Molecular Sciences, vol. 11, no. 9, pp. 3529-3539, 2010. 
[10] L. Jeong, M. H. Kim, J.-Y. Jung, B. M. Min, and W. H. Park, "Effect of silk fibroin nanofibers containing silver sulfadiazine on wound healing," International Journal of Nanomedicine, vol. 9, no. 1, pp. 5277-5287, 2014.

[11] B. S. Munteanu, Z. Aytac, G. M. Pricope, T. Uyar, and C. Vasile, "Polylactic acid (PLA)/Silver-NP/VitaminE bionanocomposite electrospun nanofibers with antibacterial and antioxidant activity," Journal of Nanoparticle Research, vol. 16, no. 10, 2014.

[12] A. Toncheva, M. Spasova, D. Paneva, N. Manolova, and I. Rashkov, "Polylactide (PLA)-based electrospun fibrous materials containing ionic drugs as wound dressing materials: a review," International Journal of Polymeric Materials and Polymeric Biomaterials, vol. 63, no. 13, pp. 657-671, 2014.

[13] J. I. Kim, H. R. Pant, H.-J. Sim, K. M. Lee, and C. S. Kim, "Electrospun propolis/polyurethane composite nanofibers for biomedical applications," Materials Science and Engineering $C$, vol. 44, pp. 52-57, 2014.

[14] R. Erdem, I. Usta, E. Sancak, D. Kocak, and M. Akalin, "Effect of propolis extract to morphology of electrospun polyurethane nanofibers," Nano Studies, vol. 7, pp. 21-26, 2013.

[15] C. Asawahame, K. Sutjarittangtham, S. Eitssayeam, Y. Tragoolpua, B. Sirithunyalug, and J. Sirithunyalug, "Antibacterial activity and inhibition of adherence of Streptococcus mutans by propolis electrospun fibers," AAPS PharmSciTech, vol. 16, no. 1, pp. 182-191, 2014.

[16] T.-H. Nguyen, Y.-H. Kim, H.-Y. Song, and B.-T. Lee, "Nano Ag loaded PVA nano-fibrous mats for skin applications," Journal of Biomedical Materials Research Part B: Applied Biomaterials, vol. 96, no. 2, pp. 225-233, 2011.

[17] E. Adomavičiute, S. Stanys, M. Žilius, V. Juškaite, A. Pavilonis, and V. Briedis, "Formation and biopharmaceutical characterization of electrospun PVP mats with propolis and silver nanoparticles for fast releasing wound dressing," BioMed Research International, vol. 2016, Article ID 4648287, 11 pages, 2016.

[18] S. Pupkevičiūtè, E. Adomavičiūtè, A. Pavilonis, S. Stanys, and I. Prosyčevas, "Formation and antibacterial property analysis of electrospun PVA nonwoven material with a small amount of silver nanoparticles," Fibres and Textiles in Eastern Europe, vol. 23, no. 6, pp. 48-54, 2015.

[19] S. Pupkevičiute, E. Adomavičiute, and S. Stanys, "Analysis of structure of electrospun nonwoven mats from pure PCL nano/micro fibres," Materials Science, vol. 19, no. 3, pp. 295-300, 2013.

[20] K. Ramanauskiene, A. Stelmakiene, and D. Majiene, "Assessment of lemon balm (Melissa officinalis L.) hydrogels: quality and bioactivity in skin cells," Evidence-Based Complementary and Alternative Medicine, vol. 2015, Article ID 635975, 7 pages, 2015.

[21] P. Tonglairoum, T. Ngawhirunpat, T. Rojanarata, R. Kaomongkolgit, and P. Opanasopit, "Fabrication of a novel scaffold of clotrimazole-microemulsion-containing nanofibers using an electrospinning process for oral candidiasis applications," Colloids and Surfaces B: Biointerfaces, vol. 126, pp. 18-25, 2015.

[22] W. Samprasit, P. Akkaramongkolporn, T. Ngawhirunpat, T. Rojanarata, R. Kaomongkolgit, and P. Opanasopit, "Fast releasing oral electrospun PVP/CD nanofiber mats of taste-masked meloxicam," International Journal of Pharmaceutics, vol. 487, no. 1-2, pp. 213-222, 2015.

[23] M. Ikeuchi, R. Tane, and K. Ikuta, "Electrospray deposition and direct patterning of polylactic acid nanofibrous microcapsules for tissue engineering," Biomedical Microdevices, vol. 14, no. 1, pp. 35-43, 2012.

[24] H. T. Au, L. N. Pham, T. H. T. Vu, and J. S. Park, "Fabrication of an antibacterial non-woven mat of a poly(lactic acid)/chitosan blend by electrospinning," Macromolecular Research, vol. 20, no. 1, pp. 51-58, 2012.

[25] H.-W. Kim, H.-S. Yu, and H.-H. Lee, "Nanofibrous matrices of poly(lactic acid) and gelatin polymeric blends for the improvement of cellular responses," Journal of Biomedical Materials Research Part A, vol. 87, no. 1, pp. 25-32, 2008. 

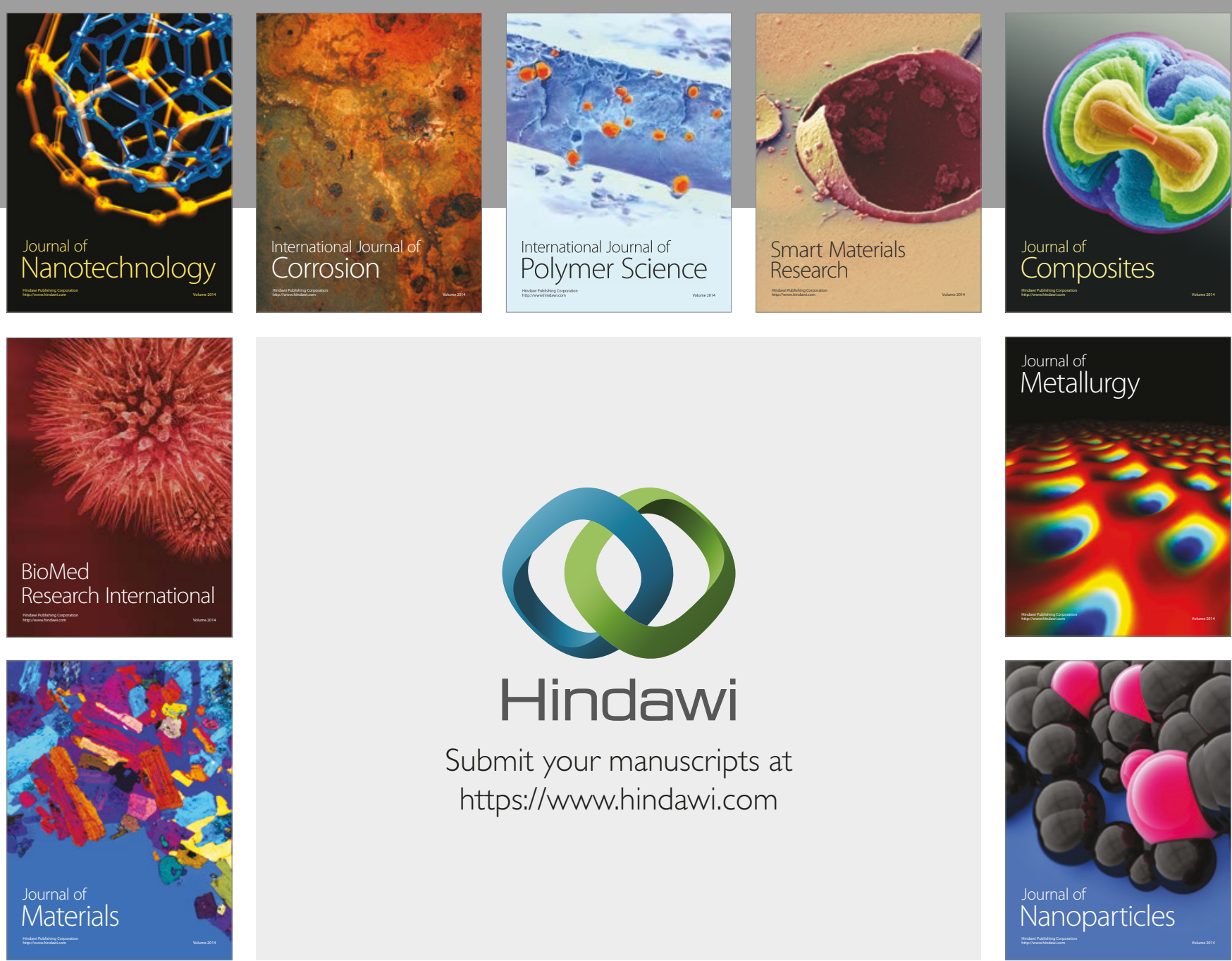

\section{Hindawi}

Submit your manuscripts at

https://www.hindawi.com
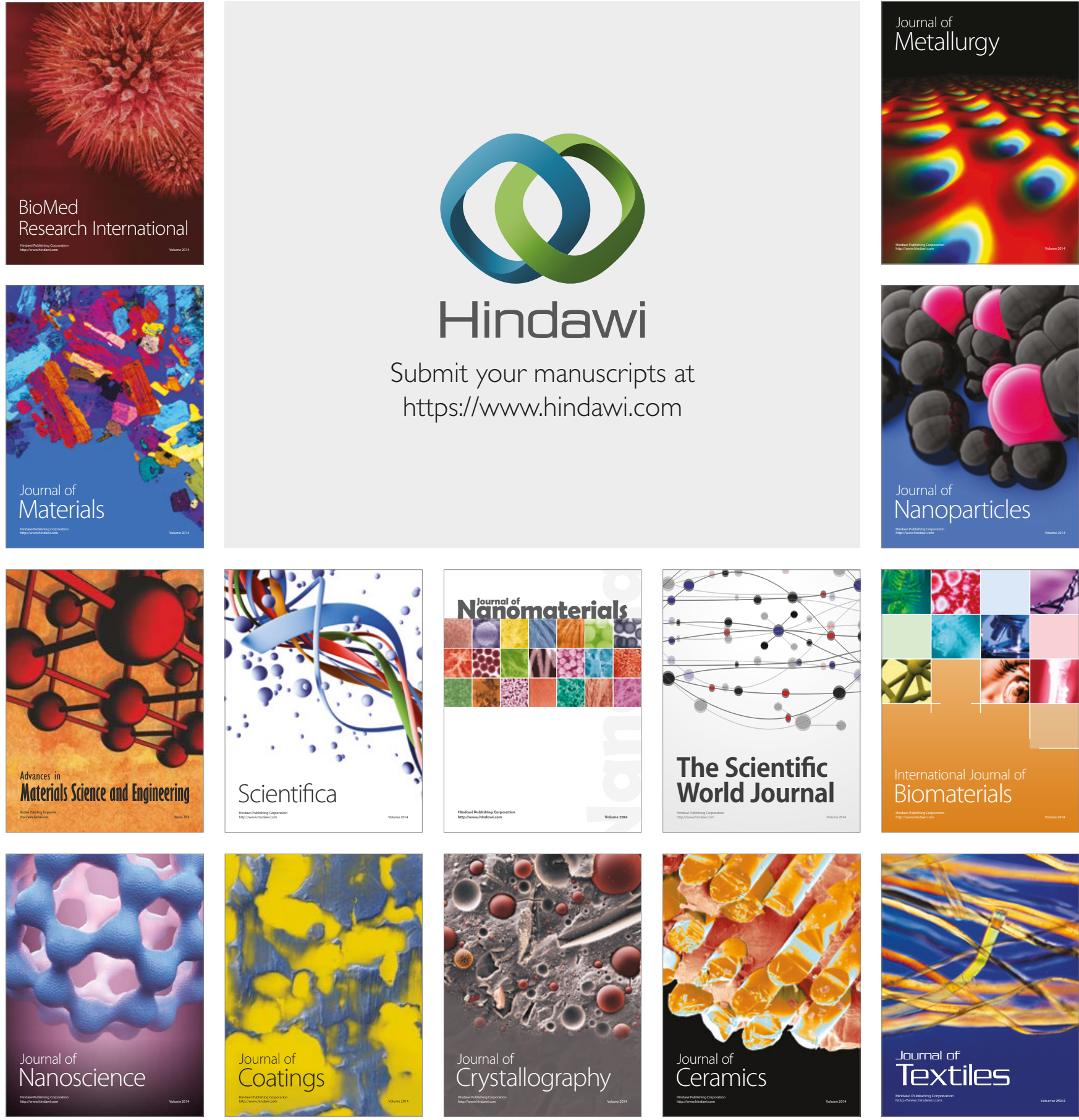

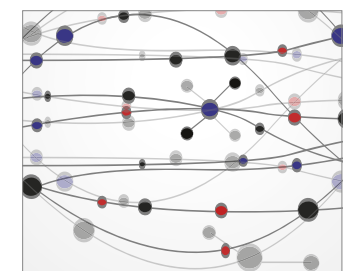

The Scientific World Journal
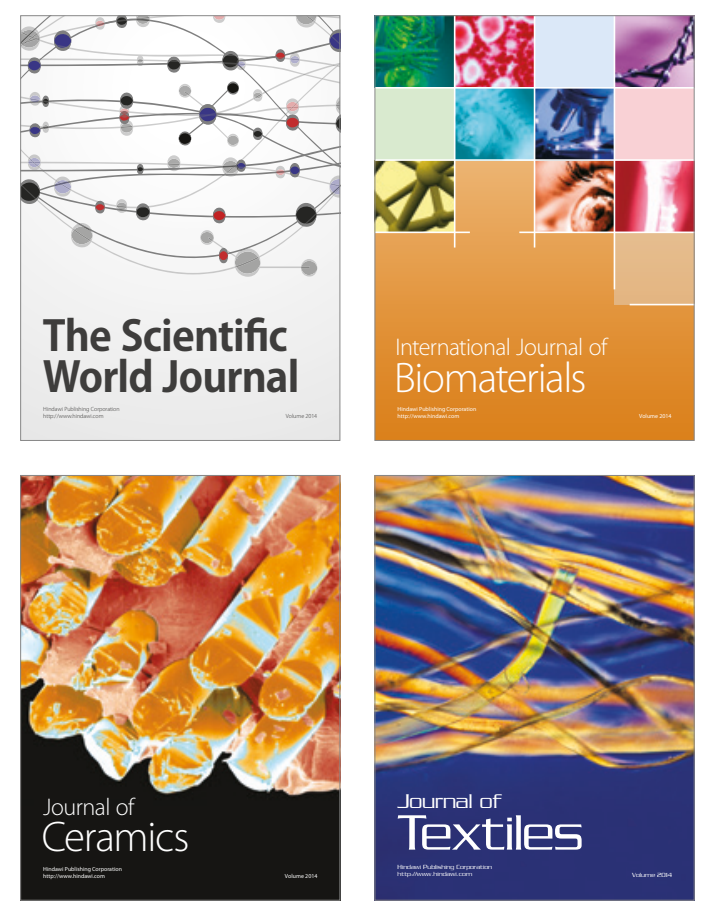